\title{
P-0556, Insulin A-chain autoreactive T cells identified from newly diagnosed type 1 diabetic patients
}

\author{
János Tibor Kis ${ }^{1,2}$, Péter Engelmann1, 3, Geoffrey Richman', Heyam Jalahej ${ }^{1}$, Tihamér Orbán ${ }^{1}$ \\ ${ }^{1}$ Joslin Diabetes Center, Boston, MA 巴) ${ }^{2}$ Polyclinic of the Hospitaller Brothers, Budapest, Hungary; \\ ${ }^{3}$ University of Pécs, Hungary
}

Background: $\mathrm{T} 1 \mathrm{DM}$ is characterized by the $\mathrm{T}$ cell dependent destruction of the insulin producing pancreatic $\beta$-cells in humans. The number of suspected target antigens is still increasing, and there is no consensus regarding the nature of the pivotal antigen. One of the most verisimilar antigens is the insulin or the proinsulin itself. The full length insulin in high dose can not be used by interventional studies, because of it's metabolic effect, therefore the identification of the exact epitope is crucial. Sally et al. isolated and oligoclonally expanded $\mathrm{T}$ cells from diabetic subjects pancreas surrounding lymph nodes, which recognized the insulin A 1-15 epitope. The publications identifying the diabetic specific autoantigens are very limited. Nevertheless in numerous intervention trials several different antigens were used to slow or block the destruction of $\beta$-cells.

Aim: We hypothesized that the autoreactive $\mathrm{T}$ cells can be identified from peripheral blood of newly diagnosed T1DM patient. We also aimed to identify which antigen is recognized by T cells.

Methods: Six newly diagnosed T1DM patients (ndT1DM) and 6 healthy individuals were involved to the study. PBMCs (peripheral blood mononuclear cells) were obtained from fresh blood by Ficoll (Amersham Pharmacia Biotech Europe $\mathrm{GmbH}$, Uppsala, Sweden) gradient centrifugation as the standard protocol. The cells were divided into 96 wells plates. The cells were cultured for 7 days without antigen, and with tetanus toxoid (TT), proinsulin (PI), insulin (I), B-chain (B), GAD protein (GAD), and insulin overlapping peptides (OP). Antigen concentrations were: $10 \mu \mathrm{g}$ and $30 \mu \mathrm{g}$ for PI, $10 \mu \mathrm{g}$ and $30 \mu \mathrm{g}$ for I, $1 \mu \mathrm{g}$ and $5 \mu \mathrm{g}$ for $\mathrm{GAD}, 25 \mu \mathrm{g}$ and $50 \mu \mathrm{g}$ for $\mathrm{B}$, and $40 \mu \mathrm{g}$ for overlapping peptides $/ 1 \mathrm{~mL}$. In each wells 150,000 cells were cultured in cRPMI for 7 days. The activation was measured with ${ }^{3} \mathrm{H}$ thymidine incorporation.

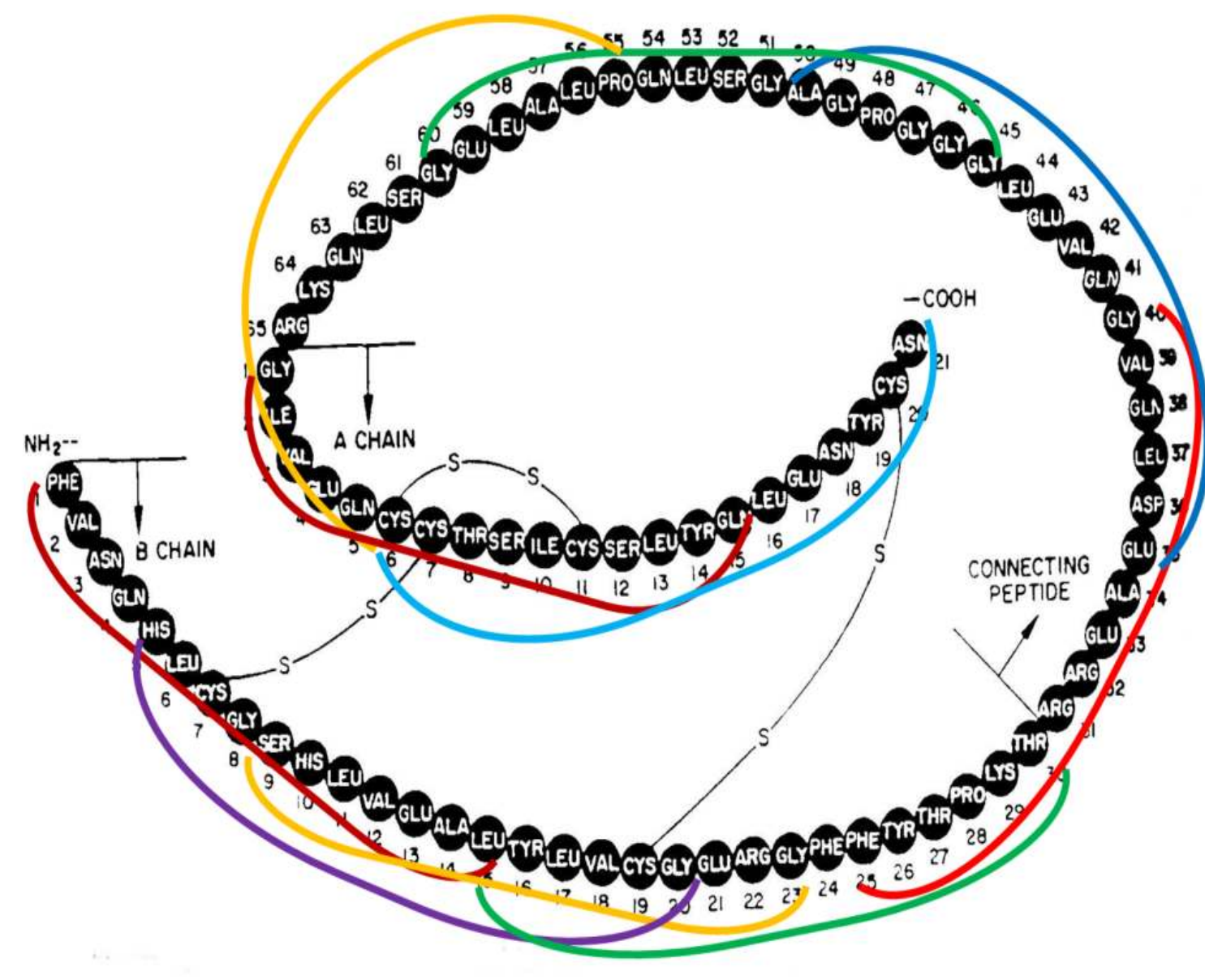

Fig. 1.

Localization of the applied overlapping peptides in the amino acid sequence of proinsulin.

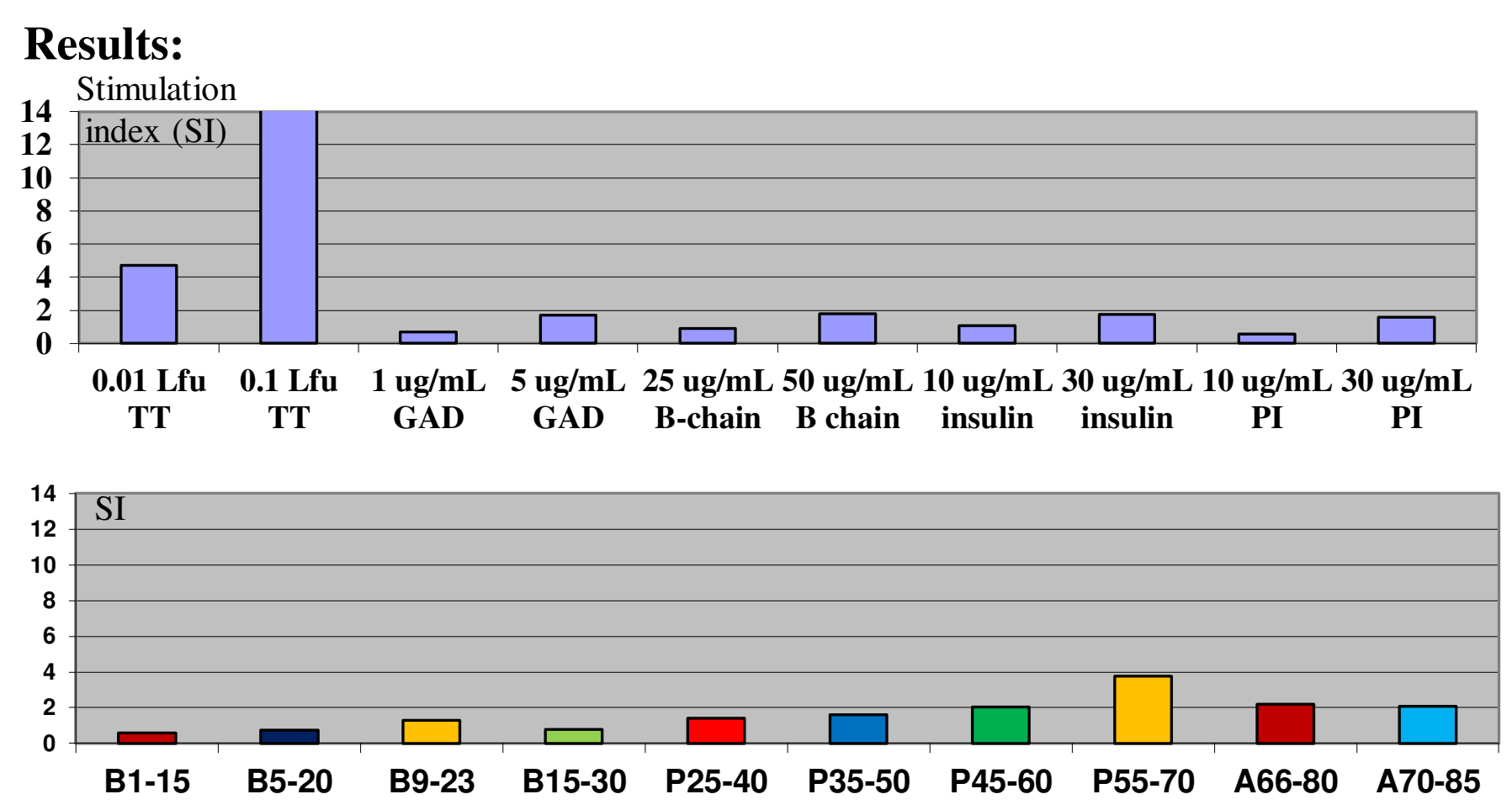

Fig. 2.

Typical stimulation assay of a ndT1DM patient.

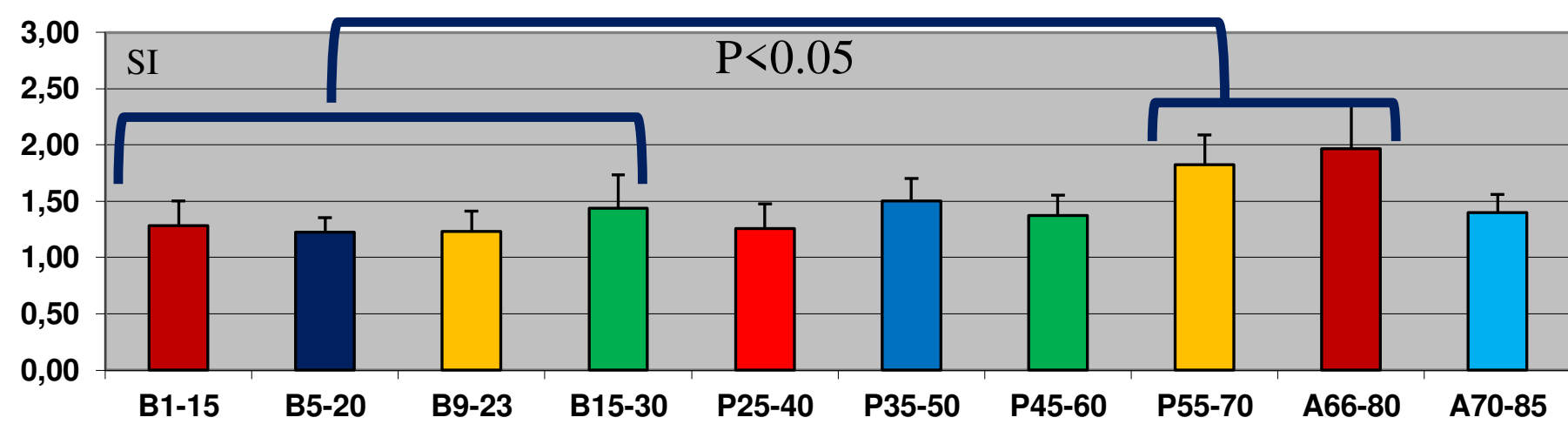

Fig. 3.

Averages [SEM] of the stimulations indexes of OP-es, 8-9 peptides resulted significant higher $(P<0.05)$ stimulation of the PBMC-s derived from 6 ndT1DM patients than the $B$ chain peptides.

Results: Among the diabetic-related antigens the
highest activation was measured with those
overlapping insulin peptides, which contained the first
5 amino-acids of the A chain. Lymphocytes derived
from healthy individuals did not recognize any of the
examined antigens.
Conclusion: PBMCs derived from ndT1DM patients
identified almost the same part of the proinsulin as the
lymph node originated T cells. If the pivotal antigen
does exist, it's identification is crucial, because
probably it can be used most successfully in tissue
specific autoantigen intervention studies to halt or
delay disease progression to T1DM, as well as to
reverse T1DM. Our results suggest, that among the
insulin oligopeptides the most suspected epitope is on
the A chain.

References:

Kent SC, et al: Expanded T cells from pancreatic lymph nodes of type 1 diabetic subjects recognize an insulin epitope. Nature 2005;435:224-228.

Orban T, Kis JT.: Prevention of Type 1 Diabetes Mellitus using a Novel Vaccine.

Therapeutic Advances in Endocrinology and Metabolism 2011;2:9-16.

Orban T, et al: Autoantigen-specific regulatory T cells induced in patients with Type 1

Diabetes Mellitus by Insulin B-chain immunotherapy. Journal of autoimmunity

2010;34:408-415. 